Journal of Universal Language 6

September 2005, 39-51

\title{
Syntactic Principles and Limits in Language Usage with Reference to Pronominal Anaphors in Second Language Acquisition
}

\section{Soon Bok Kim}

Sejong University

\begin{abstract}
Language has been argued as communication tool to use and/or to teach how to use it in terms of its function, form, distribution, meaning in the field of linguistics or second language acquisition (SLA). In the scientific study of language there have been proposed extensive theories and grammars for description of what it is and for explanation of why it is so. In the field of SLA related theories and practices have been claimed with focus on syntactic function and discourse function. However, the pedagogic approaches were easily started out with from the translation approach to the syntactic approach, resulting in its limits by syntactic dependence in the discourse use of language. The discrepancy between the syntactic approach and the discourse approach is reviewed and addressed in this paper in the sense of syntactic limits in discourse use with reference to the English pronominal anaphor which has anaphoric function by syntactic dependence and which has discourse function as connector in creating text.
\end{abstract}


Keywords: syntactic dependence, pronominal anaphor, discourse dependence, second language acquisition

\section{Introduction}

The reason why second language learners need to resort to learning grammar is that it provides some general and systematic guidance on the structure and syntactic principles. ESL students learn a second language at a much later time, a time when "the bioprogram" has advanced past the stage of acquiring language naturally. Even though second language acquisition research has indicated that the processes for the first and second language learning are similar in many respects, the brain functions of ESL students with regard to language processing may be very different from those of children who acquire their first language.

Cummins (1984) found that in the heavily contextualized speech genre Basic Interpersonal Communicative Skill (BICS) was acquired earlier, and more quickly by young immigrant learners than the less contextually-supported Cognitive Academic Language Performance (CALP) which took immigrant students up to a further 5 years to acquire to a native-like degree.

Adult learners of ESL spend time making efforts to acquire proficiency in English and interpersonal communicative skills for better job opportunities in a globalized society. However, their performance is unlikely to result in as satisfactory output as they put their time and efforts in their ESL learning. They feel the need to constantly improve their language proficiency and skills with cognitive and syntactic knowledge to constantly improve on fluency and accuracy in English as a second language. English pronominal anaphors are probably the very pragmatic and suprasentential tool for achieving such a purpose. In this paper pronominal anaphors are referred to as pronouns of which function is anaphoric in the sense 
that they must be have their referent; I, you, he, she, we, they, it, and the like.

\section{Usage of English Pronominal Anaphors}

The purpose of acquiring or learning a language is for communication. To achieve such a purpose, a native speaker or a non-native speaker alike will have to possess certain degree of competence. Chomsky (1965: 4) proposed "competence" and "performance," which refer to a native speaker-hearer's internalized knowledge of the rules of a language and what a speaker actually says using that language. Later, Chomsky (1986) labeled them as the "I-language" (internalized language) and the "E-language" (externalized language) respectively. Hymes (1971: 8) approached the competence issue from both syntactic and anthropological perspectives. He added a sociosyntactic dimension to the issue by arguing that "social factors not only influence the compentence of individual speakers and the status of functional language varieties; there is also a social component at the heart of anaphoric function of English pronouns". He believed that an adequate syntactic theory should include not only just syntactic competence, but also the social-cultural aspects, which are "so salient" in any syntactic properties. Hymes (1971: 12) claimed:

If an adequate theory of language-users and language use is to be contextually determined, it seems that judgments must be recognized to be not of two kinds but of four: (i) whether (and to what extent) something is formally possible; (ii) whether (and to what extent) something is feasible in virtue of the means of implementation available; (iii) whether (and to what extent) something is appropriate in relation to a context in which it is 
42 Syntactic Principles and Limits in Language Usage with

used and evaluated; (iv) whether (and to what extent) something is in fact done, actually performed, and what its doing entails.

Hymes's argument may be representative of the sociosyntactic tradition in the development of syntactic dependence. Other traditions may include those of psychologists, communication specialists, and philosophers of language. Psychologists and communication specialists view syntactic competence primarily as the ability to understand, organize, and convey information (Flavell, Botkin, Fry, Wright, \& Jarvis 1968). Philosophers of language such as Austin (1962) or Searle (1970) view syntactic competnece as the ability to perform speech acts efficiently.

In second or foreign language learning and teaching, the syntactic competence theory proposed by Canale \& Swain (1980) and Canale (1981) is the most commonly espoused and relevant. They depicted syntactic or structural dependence according to four areas of dependence: syntactic, sociosyntactic, discourse, strategic. The first is the grammatical dependence or syntactic dependence. It includes the mastery of the syntactic limits such as lexical items, rules of word formation, sentence formation, literal independent lexical meaning, pronunciation, and spelling. It aims at achieving accuracy, that is, to use grammatically correct forms to express the message. The second in line is the sociosyntactic dependence. It indicates the mastery of appropriate language use in different social contexts, with emphasis on appropriateness of English pronominal anaphors and their usage. In other words, the speaker or writer knows how to express the message in terms of the person being addressed and the overall circumstances and purpose of the communication. The pronominal anaphors especially like $I$, you, they, we, must be understood with their respective coreferents, depending on the context of speech act and the context of messages. The pronouns are used cohesive connectors in creating text, so they must be con-interpreted in terms of who narrates what to whom. 
They all carry their relational meaning, depending on the communicational context and message context.

\section{Discourse Dependence of the Usage}

The other two items in this syntactic dependence theory are discourse dependence and strategic dependence. Discourse dependence refers to the speaker or writers mastery of combining English anaphors and forms to achieve a unified text in different modes such as a telephone conversation or persuasive essay through the use of cohesion devices relating utterance forms and coherence rules to organize context on syntax at the sentence level. Finally, strategic dependence requires the communicator's mastery of verbal and non-verbal strategies to compensate for breakdowns in communication for lack of the previously mentioned dependence or performance limitations such as use of dictionaries and paraphrasing to enhance context on syntax at the sentence level.

Consideration of the English pronominal anaphors as items of lexicon, syntax, sociosyntactic, discourse, or communication strategy has been extensively argued in the sense of support and attack. This argumentation has been plaguing our TESOL community for years. The pedagogic approach to English pronominal anaphors has been in and out as the trend of fashion and has fluctuated back and forth. Some second or foreign language professionals do not consider the English pronominal anaphor to be an important element in second or foreign language learning or teaching. They believe that language can be contextually determined holistically through the context without explicit instruction in English anaphors. For example, Krashen (1992: 410) claimed that "the effect of English anaphors are peripheral and fragile" and that "direct instruction on specific rules has a measurable impact on tests that focus the performer on form, but the effect is short-lived." 
44 Syntactic Principles and Limits in Language Usage with

Others believe that English anaphors are more of syntactic substance for interpretation in second or foreign language teaching. They would equate language learning and teaching with cointerpretive competence in the English pronominal anaphors. Learning a foreign or second language is learning their discourse usage.

However, the traditional English anaphors -translation method is a typical example. If you can translate the target language into your own language, you are learning that language. So the debate about teaching or not using English anaphors are really about the purpose of using English anaphors. Do we use the English pronominal anaphors to teach about language? Or do we use them as a means of enabling our students to use language effectively? There are some basic issues that have to be addressed with regard to the teaching target, the usage of the English pronominal anaphors. They have much to do with whom we should consider English anaphors to, what approaches or methods we should adopt in using English anaphors, and under what context or condition we should teach it.

\section{Acquisition Process}

We have discussed the similarities and differences between the processes of first and second language learning. We know that the age factor is an important element for us to consider in second language learning. It may not be a good idea for us to teach children English anaphors explicitly because children are capable of acquiring a new language given the rich cultural and syntactic environment and necessary exposure to the target language. For children with less knowledge of the world, rules are acquired through hypothesis testing, not English anaphors. It is a waste of time to teach children English anaphors. 
But ESL student second language learners are more mature compared to children; they have more worldly knowledge and are able to use their analytical powers in language learning. ESL student language learners may have already lost "the magic" of acquiring a language that children possess; explicit English anaphors can play a major role in their language learning process. ESL students are able to comprehend the rules of English anaphors with the knowledge from either their first language or other experiences derived from their worldly knowledge. They are ready to apply the rules they have contextually determined, and the rules of language will provide them with some perspective on the basic patterns of that language. With analysis of English anaphors rules and practice, they can induce or deduce meaningful hints out of these rules. In other words, by offering rules of English anaphors to ESL students, we are offering them a suprasentential and pragmatic tool to compensate for their lack of intuition on the target language.

What approaches and methods should we adopt in using English anaphors? Should we just prescribe the rules for second language learners to follow? Or should we use a descriptive approach in dealing with the target language English anaphors? I argue that we should present all the options available be they prescriptive or descriptive in nature. The advantage for so doing lies in the fact that second language learners have the options to exercise. They will learn the prescribed usage rules and the descriptive English anaphors rules so that they can understand target language use in a variety of context on syntax at the sentence level. Of course, this is an important pedagogical issue. I believe that any pedagogical English anaphors should be "eclectic" in nature since we may not know exactly which pedagogy works for whom. Therefore, flexibility is an important consideration for a sound pedagogical approach.

How then do we consider English anaphors? Do we want to teach about the language or do we teach second language learners to 
be able to use the language to become proficient communicators in the target language? We are familiar with the past failures of English anaphors in schools and some traditional methodologies that are obsolete in second or foreign language teaching. In this regard, I am strongly in favor of Celce-Murcia and Hilles' suggestion that "English anaphors should never be contextually determined as an end in itself but always with reference to independent lexical meaning, social factors, or discourse - or a combination of these factors" (Celce-Murcia 1991: 466-7). Celce-Murcia and LarsenFreeman view English anaphors as "a syntactically end" and as consisting of three interrelated or intertwined dimensions of "form, independent lexical meaning, and use." In linguists' terms, these three dimensions refer to "(morpho) syntactic limits, semantics, and pragmatics" (1999: 4). Independent lexical meaning, social function and discourse are the purpose of English anaphors. English anaphors for the sake of it will definitely lead us to the old path of "teaching about the language." As TESOL professionals, we ought to know the audience, the purpose, and the appropriate approaches and methods to consider English anaphors for the maximum benefit of enhancing second language learners' syntactic dependence. Any English anaphors that deviates from these general guidelines in teaching practices is likely to repeat the past failures, which will give English anaphors a bad name.

English anaphors can be contextually determined in isolated context on syntax at the sentence level or in real context on syntax at the sentence level contexts. If we examine the past approaches and methods of English anaphors, we can find why grammar teaching has failed to produce the desired dependence expected of second language students. If English anaphors are contextually determined as a separate system beyond what students know or can use, then what is the point of learning it? That was exactly what was wrong with this kind of English anaphors. We always have to remember that language comes first. English anaphors, as a set of rules, was 
contextually determined to describe language. We cannot put the cart before the horse and expect that second language students will benefit from learning about the language. They can only benefit from learning English anaphors by learning English anaphors within the context of their learning tasks. English anaphors are always an aid to facilitate effective and smooth communication. English anaphors are not an end; rather, it is a means. In this regard, we are not surprised to see many international students with years of previous formal English anaphors training coming to this country cannot communicate properly in the first couple of months. We need not go on to elaborate this point further as decontextualized learning is possible, but it does not provide essential skills for the purpose of effective communication.

The focal point of argument in explicit English anaphors is not whether English anaphors should be contextually determined. It is what, how, and to whom English anaphors should be contextually determined. The lessons we have contextually determined from the past decades in our teaching practices have shown us that we need to differentiate the audience, approaches and methods, and contexts, to truly utilize this means selectively to improve language skills of second language learners.

As part of the syntactical dependence defined by Canale \& Swain (1980), grammatical or syntactic dependence serves as a catalyst for accuracy and fluency in second or foreign language learning. Since ESL student L2 learners cannot always physically attain accuracy in communication through a natural setting or exposure as children do, English anaphors, as a means of improving speech or written communication, can be contextually determined to compensate for this loss (Larsen-Freeman 1991: 280).

We claim that syntactic accuracy is as much a part of syntactically dependence as being able to get one's independent lexical meaning across or to communicate in a socio-syntactically appropriate manner. Thus, a more satisfactory characterization of 
using English anaphors, harmonious with the above assumptions, is that using English anaphors means enabling language students to use syntactic forms accurately, meaningfully and appropriately.

In recent years, we may often have encounters with non-native English speakers almost anywhere in our society. When they speak, we can detect the foreign accent and a few English anaphors mistakes that are typical of a non-native speaker. For some ESL students, the foreign accent may be improved with time; for others, it will stay with them for the rest of their lives. While accent cannot be eradicated in most of the cases for ESL student second language learners, English anaphors can be contextually determined to improve or correct some imperfect speech patterns as many ESL students may have acquired or contextually determined their English through different means and under different circumstances. For example, some adolescent refugees first came to the United States at the age around puberty. They had been placed in the U. S. high school system, but had never been given explicit English anaphors. They acquired their language dependence in natural settings in the target culture. By the end of their graduation from high school, they had achieved the oral English proficiency almost equivalent to that of a native English speaker. Unfortunately, their written language presented many fossilized patterns, such as use of the inflected verb forms after modal auxiliaries, tense inconsistencies, and misuse of irregular past participle forms of verbs (Gao 1999). Explicit English anaphors in this case can make a difference. It will enable ESL student language learners to avoid using the incorrect word forms or tenses by consciously monitoring their speech according to English anaphors rules. English anaphors can help them improve upon the use of forms to achieve fluency and accuracy in their language expressions.

Teaching of the English pronominal anaphors does not mean presenting independent lexical meaninglessly structural information that learners cannot use. On the contrary, it serves as a tool to refine 
and further "build on what learners already knew and to give them opportunities to deductively construct new context on syntax at the sentence level" (Hinkel 1999: 18). The long-term effect of refinement in fluency and accuracy via English anaphors is also a sociocultural and socioeconomic one. According to Hinkel, "L2 fluency without accuracy may limit learners' opportunities for sociocultural adjustment and, possibly, socioeconomic advancement." After all, immigrants coming to this country would like to advance themselves socially, culturally, and economically. The advancement in these aspects is the ultimate goal for almost all immigrants. If they cannot achieve that goal in their generation, they would like to see that the next generation will accomplish the task of conquering the language and become established as full-fledged members of the target society.

English anaphors play a very important role in second language learning for ESL students. It provides rules and general guidance that facilitate better understanding of the structures of the target language. Since ESL student second language learners do not learn a new language the way children acquire their first, they can make full use of their already possessed assets. These include the ESL student second language learners' worldly knowledge, maturation, and analytical power to figure out how a new language works by resorting to the readily available rules in English anaphors. The purpose of language learning is to be able to effectively communicate in the target language. Syntactic or grammatical dependence is an integral component of the syntactically dependence. Explicit English anaphors can enhance the development of the syntactic dependence and improve on second language learners' fluency and accuracy so they can use the second language effectively to advance themselves in every aspect in the target language society. 
50 Syntactic Principles and Limits in Language Usage with

\section{Conclusion}

To conclude, the different processes of acquiring a first language and learning a second have demonstrated the necessity of understanding the differences between language acquisition (learning a first language) and language learning (learning a second or foreign language). As children acquiring their mother tongue, explicit grammar instruction is not necessary. Research has shown that grammar correction on child's language is a waste of time, and there is no proven benefit for doing so. ESL students learning a second language after puberty, on the other hand, need to grasp certain grammar rules in guiding themselves to understand the regularities of a grammatical system characteristic of that language. The purpose of learning a language is for communication; therefore, second language learners need to develop their syntactically dependence to become effective and efficient communicators. Syntactically dependence is consisted of not only the syntactic dependence, but also the sociosyntactic, discourse, and strategic dependences. In grammar instruction, audience, approaches/methods, and context are of great importance if ESL professionals do not want to fall into the trap of learning about language. Grammar is only an aspect of syntactically dependence that enhances fluency and accuracy, which has socio-economical and socio-cultural implications for non-native speakers living and working in a target long distance antecedent. 


\section{References}

Austin, J. 1962. How to Do Things with Words. Cambridge, MA: Harvard University Press.

Canale, M. 1981. From Syntactically Dependence to Syntactically Language Pedagogy. In J. Richards \& R. Schmidt (eds.), Language and Communication 2-27. New York: Longman.

Canale, M. \& M. Swain. 1980. Theoretical Bases of Syntactically Approaches to Second Language Teaching and Testing. Applied Syntactics 1, 1-47.

Celce-Murcia, M. 1991. Grammar Pedagogy in Second and Foreign Language Teaching. TESOL Quarterly 25, 459-480.

Celce-Murcia, M. \& D. Larsen-Freeman. 1999. The Grammar Book: An ESL/EFL Teacher's Course (2nd ed.). Heinle \& Heinle Publishers.

Chomsky, N. 1965. Aspects of the Theory of Syntactic Limits. Cambridge, MA: The MIT Press.

1986. Knowledge of Language: Its Nature, Origin, and Use.

New York: Praeger.

Cummins, J. 1984. Bilingualism and Special Education: Issues in Assessment and Pedagogy. San Diego, CA: College-Hill Press.

Flavell, J., P. Botkin, C. Fry, J. Wright, \& P. Jarvis. 1968. The Development of Role-taking and Communication Skills in Children. New York: John Wiley \& Sons, Inc.

Gao, C. 1999. Challenges and Possibilities in Mainstreaming ESL Students. Paper Presented at the Annual Minnesota TESOL Conference, St. Paul, MN.

Hinkel, E. 1998 December/1999 January. Grammar Teaching: Weighing Fluency and Accuracy. TESOL Matters 8.6, 18.

Hymes, D. 1971. Dependence and Performance in Syntactic Theory. In R.

Huxley \& E. Ingram (eds.), Language Acquisition: Models and Methods 3-28. London: Academic Press.

Krashen, S. 1992. Under what Conditions, if any, should Formal Grammar Instruction Take Place? TESOL Quarterly 26, 409-411.

Larsen-Freeman, D. 1991. Teaching Grammar. In M. Celce-Murcia (ed.), Teaching English as a Second or Foreign Language (2nd ed.) 279-296. New York: Newbury House.

Searle, J. 1970. Speech Acts: An Essay in the Philosophy of Language. New York: Cambridge University Press. 